\title{
ENCULTURATION IN THE LIFE PATTERN OF BREAST CANCER PATIENTS: AN ETHNO-NURSING STUDY ON SUNDANESE WOMEN
}

\author{
Witdiawati, Laili Rahayuwati, Sheizi Prita Sari \\ Faculty of Nursing, Universitas Padjadjaran \\ Email: laili.rahayuwati@unpad.ac.id
}

\begin{abstract}
Introduction: Death of breast cancer remains the highest position in the totem of incidents not only in Indonesia but also in the world. Its treatment process, which in fact brings huge impacts to the life quality of breast cancer patients regarding physique, psychology, and social life, shapes some behavioral patterns throughout their life. The aim of this research is thus to explore patterns of breast cancer patients in sustaining their lifespan. Method: This research is designed using ethno-nursing qualitative approach. The sampling technique is done purposively to 6 informants, all of whom are breast cancer patients in Garut District, West Java, Indonesia. Data collecting is done through interviews and participatory observation. Data transcription is analyzed using ethno-nursing analysis method. Results: The result of the research shows four domains occurring as a pattern of inculturation of breast cancer patients in Sundanese culture, namely 1) dedication as wife and mother of Sundanese breast cancer patients, 2) medicine seeking for the rest of their life, 3) factors affecting to breast cancer patients adaptation for daily routines, and 4) family gathering as a meaning for end of life. Discussion: The result of this research shows an interconnected cultural pattern in the life of these patients. It is thus advised that nurses provide service to breast cancer clients by applying nursing care inherent to their cultural values.
\end{abstract}

Keywords: life-pattern, breast cancer, ethno-nursing.

\section{INTRODUCTION}

Any diagnosis is a life-changing experience for some people; breast cancer is no exempt. It is considered the road to death by some people in general. This consideration might more or less destabilize life quality of breast cancer clients and their family. Upon being diagnosed with breast cancer, the client must undergo several medical procedures that obviously takes a long time or even for the rest of their life, during which many changes will emerge in their daily routines. The resulting condition of this process brings impacts to their life regarding physique, psychology, and social life. Changes of role, perception, coping mechanism and behavior of seeking healthcare have come to be seen as a response to the meaning of cancer itself. Furthermore, trauma and indeterminacy of breast cancer diagnosis can affect the client's psychological and spiritual prosperity (Lopez-Class et al. 2011).

Some cultures believe that, for women, having breast cancer is a heavy burden to carry. However, the state of ill and healthy is highly relative due to some relevant factors. The term "ill" per se contains many different meanings regarding culture, social, and occupation. It is the fundamental aspect in determining illness, for it is a social recognition with which someone can play their normal role as people expect them to. Therefore, many social and cultural factors do affect the life of these clients.

Such social aspects of illness as physique, mental, and medics will shape illness behavior. It is understood, as Lambert \& Loiselle (2007) puts it, as ways to which symptoms are responded, evaluated, and played by an individual is subjected to that illness, feels uncomfortable or reads other mal-bodily signs. Having that in mind, she can act out his normal roles partially or entirely. Illness behavior is highly affected by such factors as social classes, ethnics, and cultural differences.

Humans, as we all know, cannot live alone, for they are interdependent to each other, which applies the same way to breast cancer's clients. They have a lot of needs to fulfill and maintain their health and life quality. However, due to their powerlessness, not all of those needs could be fulfilled on their own. This is exactly 
why they are exceptionally dependent on their family members and the environment.

The family is the closest part of the life of breast cancer clients. As social theory claims it, it is defined as a group of people unified by marital, blood, or adoptive bond, in which they belong to the same house and place to live, interact and communicate to each other, play their roles as either husband, wife, mom, dad, son, daughter, brother, sister. In other words, families attempt to create and sustain general culture (Khakbazan et al. 2014).

In maintaining life quality, these clients must be able to not only receive holistic care from nurses but also nurse themselves. Leininger (2005) mentions several factors of a social and cultural dimension such as technology, religion, and philosophy, social and intimacy, cultural values, belief, ways of life, laws, and politics, economy and education. All of them affect and are affected by, how someone would be able to nurse herself. All those factors will enable the breast cancer clients to make a decision in undergoing the process of treatment and therapy.

Regarding social life, Garut district of West Java is one of the districts that embrace the Sundanese culture, which grows and lives in Sundanese society. This explains why the majority of Garut people are of Sundanese descent, although recently many ethnics have come to coexist. Sundanese is the mother tongue passed for many generations and thus becomes the main language for communication amongst Garut people. It is also known with politeness culture, enabling their characteristics to be easygoing, amiable (someah), smiley (love to smile), and highly respectful of the elderly. The people in West Java or, broadly speaking, Tatar Sunda, including Garut, are known as softspoken, religious, and spiritual. As the proverb silih asih, silih asah and silih asuh, meaning be passionate to yourself (welas asih), guide, selfimprove, and protect yourself and other people through education and many other fields. In Sundanese culture, religious harmony is maintained by rituals while social harmony by gotong royong (mutual cooperation) (Ekadjati 2014).

The familial system in Garut is bilateral, in which the descendant line is drawn from both the father and the mother. Therefore, the right and position of a family member are linear. The meaning of family for Sundanese people is seen as a shelter not only for wife and husband but also between families. A strong familial bond and Islamic teachings do affect the customs of Sundanese ethnic, or more ubiquitously known as Pancakaki.

In Sundanese family, the husband holds the position of head of the family responsible for the prosperity of all its members. Meanwhile, the wife has the duty to manage the household and take care of the children. As for widows, the chance of becoming the head of the family is bigger than wives. In Sundanese culture also, particularly in the village areas, there is a tendency for men to make decisions due to his high status in the familial hierarchy. This happens not only inside the family institution but also in the society in general.

Levels of Sundanese familial bond based on generational differences become paramount. Such difference is divided into three compartments, namely (1) the elderly (sepuh) that is, grandfather, grandmother, father, mother, and upper-age generations, (2) siblings (sadulur): spouses and stepsiblings, or also known as lanceuk if older in age and adi or rayi if younger, (3) children-that is, the descendants. The elderly (uncle, aunt, $u a-$ those younger in age than one's mother or father) in Sundanese are considered as "The Old", even when they have passed away. They still have the right to be involved in a familial discussion. They must be respected, for it is their obligation to guide The Young.

The role of illness for a Sundanese woman pesters herself, especially those who are married and have children. The duty of a wife is that she must fully submit fully to her husband (dulang tinande). However, her role as a mother is deity-like, cognizant that her child must respect her because she endured pregnancy and the inevitable pain and struggled to carry (indung anu ngandung). The illness, undoubtedly, brings significant impacts to the change of role and social status for breast cancer clients, in their relations to their role as Sundanese women.

The role of nurses as health provider is crucial in resuscitating the society of the danger of breast cancer, as well as advantages from the 
actions done to prevent breast cancer itself. In creating plans and implementing those plans, communal nurses must balance cultural values, universal human experiences, and general needs of every person. Having that in mind, they need to understand important cultural aspects of nursing, which will foster community health through skill improvement.

Although the management of breast cancer has rapidly grown, the reality says otherwise. Only a few scientific studies have observed what these breast cancer clients do throughout their life. In the framework of ethnonursing methodology, the focus of this research is on experiences and daily events of breast cancer clients in maintaining their life quality, as well as their perceptions and meanings of those experiences. Their life patterns, thus, becomes the main focus of this research.

\section{METHOD}

In the practice of nursing, the ethnographical approach is more commonly known as ethno-nursing. In other words, the nurses utilize ethnography as the basis of nursing care. Furthermore, such approach enables them to study explicitly nursing phenomena from cross-cultural perspectives.

The method of ethno-nursing research, designed by Leininger, proves helpful to use, knowing that it is a unique and essential qualitative method to study nursing and treatment practice, beliefs, and varying cultural and environmental values. Leininger (2005) also shows that this method is used to understand the meaning of the daily life of those who work in the field of nursing, healthcare, and human prosperity, in a different or similar environmental context.

The number of informants in this qualitative research is previously indeterminable, meaning the sampling might escalate throughout the research. According to Leininger (2005) and Wanchai et al. (2010), when doing a macro ethno-nursing study, 12 to 15 key informants and $24-30$ general informants have great daily needs to fulfill. On the other one, when doing micro ethno-nursing, the researcher needs $6-8$ key informants and 12 - 16 general informants. However, the majority of informants cannot be the parameter, for it can lead to skewing perspective and limited reasoning of how the treatment of special phenomena is carried out. Therefore, the aim of this research is to reach the proper number of key, general, and participatory informants, from which the data reaches its vantage point.

In this research, data saturation or no new information is reached at the $6^{\text {th }}$ informant, meaning the number of the informants for this research is limited to 6 people only. Meanwhile, participatory informants include family (2 husbands as two key informants, one child as a key informant, as well as one friend as a key informant).

\section{Research Instruments Interview}

The guideline for interviews focuses on the mundane life of breast cancer clients. This is done by trying to understand daily phenomena in the effort of maintaining their life quality. The open-ended interview is applied and probes are used and prepared by the researcher. Main data are obtained based on probing question used in the interview, during which researcher gives zero limits to clients' responses. However, supposing the informants digress in their answers, the researcher will lead them back to the main discussion. The theme of the interview includes informant's life experience from their diagnosis to their attempts to maintain their life quality. This is done in between informant's activities, as far as the researcher observes.

\section{Participatory Observation}

This research uses three observatory steps, as Leininger would put it, namely observation, participation, and reflection. The observation is done on daily activities of breast cancer patients in maintaining their life quality. Its goal is to observe behaviors and interactions among individuals of those groups in their social life. The behaviors include acts demonstrated both verbally and nonverbally.

\section{Documentary Study}

This study provides information regarding unobtainable information from (in) direct interviews. It hugely concerns both written and unwritten documents. While the former includes breast cancer client's medical records, therapy, 
and treatment, the latter includes photos taken by researcher during observation. However, not all informant's activities are documented through pictures due to some ethical reasons. One of the results is an unabridged medical record of each informant. By using medical record, it is easier for researcher to identify at which stage of cancer. Besides, it helps identify kinds of therapy and treatment that these informants have done or are doing.

\section{Tape Recorder}

The tape recorder is used as one of datacollecting equipment. Some information to be recorded are impressions of experience, thought, and feeling as contemplated by these informants. It is only used during the first interview only.

\section{Field Note}

Much of this research applies field note as data-collecting equipment. It is used throughout the interview and during observation to some informant's activities.

\section{Researcher as Instrument}

The researcher attempts to fulfill his competence as a researcher in digging out the informants' experiences. For some observatory activities, researcher mingles with the patients. This includes cooking, taking part in posyandu (maternal and child health center) activities as well as in therapy and treatment activities.

\section{Data Analysis}

This research is done by involving detailed description about the setting or individual with breast cancer, followed by data analysis through 4 steps according to Leininger (2005), as drawn in Diagram 1.

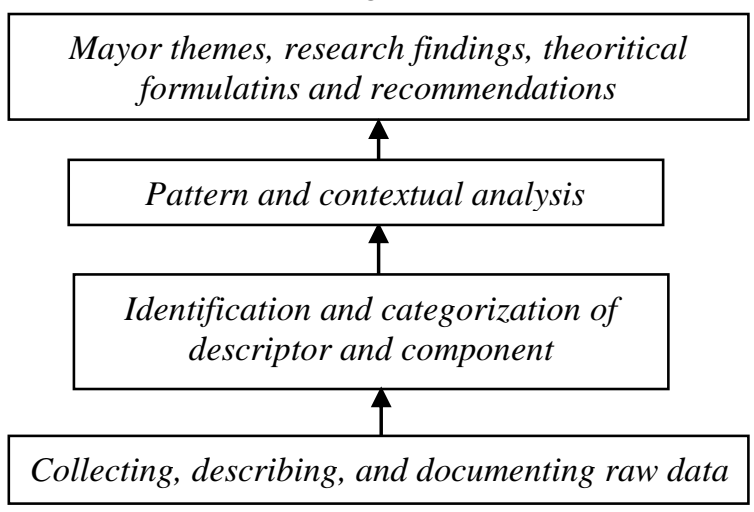

Diagram 1. Research data analysis (Leininger, 2005)

\section{Research Ethics}

This research is done with permission from Ethical Committee of Medicine Faculty Universitas Padjadjaran.

\section{RESULTS}

Based on the result there are four domains: 1) dedication as a wife and mother from Sundanese woman with breast cancer, 2) medicine discovery throughout the life of Sundanese woman with breast cancer, 3) factors affecting adaptation patterns of breast cancer clients in their routine and 4) gathering with family as the meaning before their life ends. The resulting category and domain will be discussed separately to reveal the meaning of breast cancer patient's life. However, those categories are interdependent in construing and describing the meaning of life in maintaining their life quality in this research. The schematic elaboration on research results of life pattern of breast cancer clients in maintaining their life quality based on a transcription of interview data and participatory observation shown in diagram 2 .

\section{DISCUSSION}

Living life as breast cancer clients is not an easy thing. Naturally, someone will have to adjust to harmonize her life based on the culture she believes in. However, the behavior could only be done by studying and learning it as a culture of life. Koentjaraningrat (2009) states that humans could walk because of his fundamental nature to walk, and it happens as is. On the other hand, walking like a soldier or a model could only be learned using brain. Thus, it is called "culture" defined by all thoughts and actions functionally and non-functionally determined by the society.

The illness in life will bring about different response and meaning to each individual. Transcription of the interview and participatory observation describe that illness is seen as the life cycle of breast cancer patients. The awareness of life passage is based on the role she has to play, which is a woman. For a particular culture, being a woman means carrying a huge responsibility in their life, enabling her to view illness not as a problem but a cycle to undergo. 


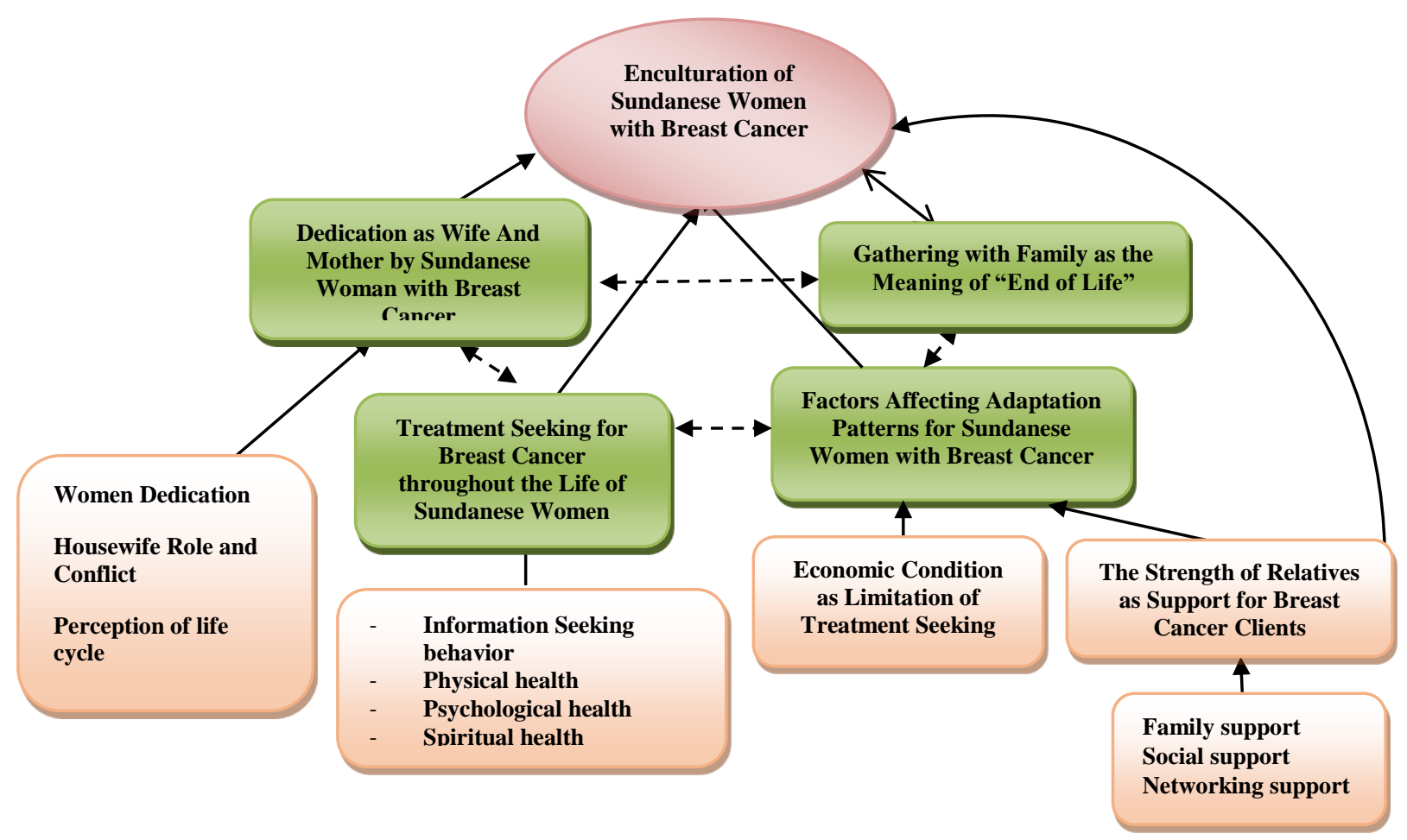

Diagram 2. Life Pattern of Breast Cancer Patients

Saefullah (2008) claims that, in Sundanese culture, different views on Sundanese women are affected by traditional values growing in Sundanese culture and Islamic teachings, which are the most adhered to religions in Sunda. Thus, a role of a woman is highly respected and holds a high position in life, as the proverb says it: indung tunggul rahayu bapa tangkal darajat (safety, happiness, and prosperity lie on mother's and father's prayers), which goes to the next expression: indung anu ngandung bapa anu ngayuga (there will be no child without the affection of mother and father). Those expressions explain the importance of women's role to their children and husband.

The view of illness and death as illness becomes a pattern drawn in breast cancer clients. Thus, many attempts are made to overcome those adversities. The life pattern to endure by breast cancer clients is different from many people, which encourages them to try many things to balance life with culture. Helman (2007) describes the proposition of illness as follows: (1) not all social or cultural groups respond to illness with the same way, (2) the way people see and respond to their illness, whether it is on their own or others, could be affected by their cultural background, (3) the way and the kind of communication of their illness for health professionals and other people, are also affected by cultural factor.

The interval between healthy and ill undergone by breast cancer clients need treatment and therapy attempt to prosper their life quality. It is learned, understood, and applied in their life, to map out as a form of "inculturation." Koentjaraningrat (2009) claims that the process of inculturation is a learning process and adapting to mind, behavior, and custom, norm systems, and all existing laws related to a particular culture. Much of the same way with what Sadono (2016) has to say: inculturation has two meanings. The first refers to the attempt of inculcating a value, behavior, feeling, view, or knowledge growing and developing in society to the members. The second refers to value aspects, norms, and behaviors under the consent of any living member of a community, which controls and 
directs the behaviors with specific objectives. Thus, inculturation might as well be called as "culturing."

Seeking behavior is a behavior constantly done by breast cancer clients throughout their life. Rankin (2011) demonstrates that, after the client being diagnosed, the family's first attempt is seek information regarding treatment of cancer. He goes on to say that problem solving and positive assessment is also positive and significant predictors from family's tendency to seek social support as caregivers.

In line with that, Jenkins et al. (2001) also claim that most patients want as much information as they could obtain about treatment and their illness. A very important finding from their research is that $98 \%$ of patients feel that they need to know what cancer is and $95 \%$ want to know the probability of their recovery. Therefore, information on prognosis does not need avoiding.

The awareness of cancer among the people and treatment system from doctor or alternatives are paramount. Thus, the information regarding diagnostic and treatment is a dire necessity (Pati et al. 2013). The individual will actively look for information on treatment and therapy (Case et al. 2005). This is linear with Balneaves et.al. (2007) in their qualitative research, claim that aftershock, anxiety, and fear of knowing their diagnosis, women with breast cancer will start to consider their choices in looking for treatment that exceeds the conventional one to maximize the benefit of treatment itself, and minimize possibility of cancer restoration.

The choice of kinds of medication done by the clients is not only that of conventional but also an alternative. Wanchai et al. (2010) claim that such choice is based on the perception that they could give benefits by fulfilling patients' need to return to Mother Nature and improving psychological and emotional recovery so that their mind becomes safe and peaceful. On the other hand, Koentjaraningrat (2009) claims that in every society, humans won't be able to ignore knowledge about others. Such knowledge on anatomy in cultures rarely touched by medical studies is surprisingly extensive too. The knowledge to cure illness in villages are done by witches or shamans and masseurs. Witchcraft typically uses much of dark magic. Besides, they also have broad knowledge about characteristics of human organs, their positions, and the structure of nerves and stuff.

Moreover, the improvement of physical health and psychological prosperity is another attempt constantly done by the clients. Eating pattern or diet as well as other nutrition fulfilling efforts are also included. This is relevant to what Ansa, et.al (2016) have to say: most respondents believe that obesity $(52,7 \%)$, less physical activity $(48.7 \%)$ and high-fat diet $(63.2 \%)$ are related to cancer restoration. Another attempt is to minimize effect from symptoms of breast cancer, such as pain.

On the other hand, the attempt to maintain psychological prosperity is made by avoiding stressor and keep her mind calm. As (Livneh 2000) says that personal control or self/cognitive restraint is another strategy employed by cancer survivors to overcome stress by the illness. This is the predictor of positive psychosocial adaptation and relieves stress.

The attempt of psychological prosperity is based on a good belief about giving meaning about illness in spiritual terms. Koltko-Riverra (2004) and Vidal (2008) claim that the view based on someone religious, spiritual, existential, or natural, is the basis of mind and behavior of that person alone.

A chain of treatment and therapy attempts to balance her life with the existing culture becomes a continuous subject to learn and do for the rest of their life. Therefore, struggling to face breast cancer becomes a constant meaning event for a Sundanese woman, thus becomes part of her culture. The result of such inculturation is described in a mapped pattern in the life of breast cancer clients.

A life cycle will be seen and learned differently from the life of everyone else. It is necessary to have a positive coping mechanism in making that happen. Adaptation pattern in someone will determine how she will live her life. Those who live in a place with a particular culture will have to submit to several universal factors affecting their life. It goes the same way with breast cancer clients. From the result, the researcher describes two factors affecting adaptation patterns of breast cancer clients in living their life: economy and socio-relative. 
Economic factors are one of the meaningful factors to the life of breast cancer clients. Change of economic conditions due to illness affects adaptation pattern of their life. Yan et al. (2016) in their research revealed that cancer is a high-class illness for patients and their health. Therefore, high income from family and health insurance plan could improve life quality of breast cancer. Lack of social and economic factors are main predictors of death among breast cancer patients (Walsh et al. 2014). In line with that, Pisu et al. (2010) claim that "out of pocket" money is a significant burden for survivors even after early treatment. Cancer economic burden is also complementary cost and psychosocial burden.

This cost, which is time value spent with illness, represents the time that could not be dedicated to common activities and considered the loss of productivity for patients and society. Meanwhile, psychosocial cost refers to the loss of life quality regarding cancer. This cost is related to anxiety, depression, cancer burden, marriage conflict, social negative change and family relation, and future indeterminacy. The total cost consists of that of productivity loss ( $89 \%$ of it) and health treatment cost $(11 \%)$ (Broekx et al. 2011).

Besides economic factor, social factor and relative factors are paramount factors for breast cancer clients. Social support from family, relative, friend, bosses from work and government also affects the adaptation pattern of breast cancer clients in living their life. Yan, et.al (2016) mentions that available social support from family member, friend, and neighbor, related significantly to improve life quality of breast cancer patients. Mokuau \& Braun (2007) concludes family as the most important source of emotional and concrete support for women with cancer. Therefore it is necessary to identify the needs to improve informational support for patients and family.

The family is the closest part of the life of breast cancer patients. They are defined as two individuals or interdependent for emotional and physical bond as well as economic support. Meanwhile, in social theory, family is a group of people united by marital, blood, and adoptive bond, where they live in one household, interact and communicate each other in their role as wife and husband, mother and father, child and daughter, brother and sister; and try to create and maintain general culture. Besides, family support is an interpersonal relation that protects someone from bad stress effect (Kaplan and Sadock, 2002).

The research of Livneh (2000), another strategy directed to relieve stress among people with cancer is to find support from other. The result of this research shows a positive relation between seeking and reporting satisfaction of social support an emotional digression and psychological restraints, psychosocial and subjective perception is higher than prosperity.

All life pattern and cycle ends up in a belief about the meaning of the end of life. It goes the same way with informants in this research. The meaning of "end of life" is described based on the life cycle of the clients as a manifestation of the illness. Many attempts to maintain life quality has been made, but there is one time where all that must stop. Izumi et al. (2012) define "end of life" as a wise period where one realizes that her life must end. It's not a period medically determined before death. The awareness of "end of life" could be raised by patient's own knowledge or result from medical assessment without patients' notice.

Breast cancer is one of death causes. This general stereotype goes all over patients with different kinds of cancer. Where attempts are made to maintain function well with illness or diagnosis that threatens life for the long term. It is then followed by extreme fizzling of condition for few weeks or months before death. This stereotype is relatively predicted after tumors become unresponsive to the medication and escalate (Izumi et al. 2012).

In other words, "end of life" becomes an inseparable meaning from life undergone by breast cancer clients. However, there is one final goal they want for the "end of life" phase - that is, gathering with family members before until their last moments. Such meaningfulness in a Sundanese culture highly affects the life of these clients up to their deathbed.

The life cycle of Sundanese women with breast cancer describes that there is one enculturation pattern in their life. Not only does it become a part connected directly to their life 
but also to other domains therefore creating an inseparable unified pattern.

\section{CONCLUSION}

Based on the result of research and analytical observation of all emerging domains, it is concluded that there is a cultural pattern in the life of breast cancer clients in living their life. This pattern becomes the behavioral basis for them throughout their life, all attempts were made to support one another in maintaining their life. Based on the existing cultural patterns, the illness they possess brings them to give meaning to life cycle so that it makes them learn, study, and apply the characteristics of treatment and medication in between their illness period to become a culture, which might be different from other people.

There is no exempt from adaptation pattern for breast cancer clients in living their life. Some universal factors also affect such pattern, which is social and kinship as well as the economy. Both factors become paramount factors in their life.

Although the end of their life pattern will meet with the phase of the end of life, they have attempted to maintain their life quality from the beginning of diagnosis to the end of their life.

The result of this research shows an interconnected cultural pattern in the life of these patients. It is thus advised that nurses provide service to breast cancer clients by applying nursing care inherent to their cultural values.

\section{ACKNOWLEDGMENT}

The opportunity and financial support for this research were provided by Ministry of Research Technology and Higher Education of Indonesia.

\section{REFERENCES}

Broekx, S. et al., 2011. The costs of breast cancer prior to and following diagnosis. The European Journal of Health Economics, 12(4), pp.311-317. Available at:

http://www.ncbi.nlm.nih.gov/pubmed/2030 6109 [Accessed May 31, 2017].
Case, D.O. et al., 2005. Avoiding versus seeking: the relationship of information seeking to avoidance, blunting, coping, dissonance, and related concepts. Journal of the Medical Library Association: $J M L A$, 93(3), pp.353-62. Available at: http://www.ncbi.nlm.nih.gov/pubmed/1605 9425 [Accessed May 31, 2017].

Ekadjati, E., 2014. Kebudayaan sunda. Suatu pendekatan sejarah., Bandung: PT Dunia Pustaka.

Helman, C., 2007. Culture, health and illness 5th ed., Hodder Arnold. Oxford University Press.

Izumi, S. et al., 2012. Defining end-of-life care from perspectives of nursing ethics. Nursing Ethics, 19(5), pp.608-618. Available at: http://www.ncbi.nlm.nih.gov/pubmed/2299 0423 [Accessed May 31, 2017].

Jenkins, V., Fallowfield, L. \& Saul, J., 2001. Information needs of patients with cancer: results from a large study in UK cancer centres. British Journal of Cancer, 84(1), pp.48-51. Available at: http://www.ncbi.nlm.nih.gov/pubmed/1113 9312 [Accessed May 31, 2017].

Khakbazan, Z. et al., 2014. Help Seeking Behavior of Women with Self-Discovered Breast Cancer Symptoms: A MetaEthnographic Synthesis of Patient Delay F. Harris, ed. PLOS ONE, 9(12), p.e110262. Available at: http://dx.plos.org/10.1371/journal.pone.01 10262 [Accessed May 31, 2017].

Koentjaraningrat, 2009. Pengantar antropologi. Pokok-pokok etnografi II, Jakarta: PT RinekaCipta.

Lambert, S.D. \& Loiselle, C.G., 2007. Health Information Seeking Behavior. Qualitative Health Research, 17(8), pp.1006-1019. Available at: http://qhr.sagepub.com/cgi/doi/10.1177/10 49732307305199 [Accessed May 31, 2017].

Leininger, M., 2005. Overview of Leininger's Ethnonursing Research Method and Process. Available at: http://www.madeleineleininger.com/cc/researchmethod.pdf [Accessed May 31, 2017]. 
Livneh, H., 2000. Psychosocial Adaptation to Cancer: The Role of Coping Strategies. The Journal of Rehabilitation, 66(2), p.40. Available at: https://www.questia.com/library/journal/1 G1-62980227/psychosocial-adaptation-tocancer-the-role-of-coping [Accessed May 31, 2017].

Lopez-Class, M. et al., 2011. Quality of Life Among Immigrant Latina Breast Cancer Survivors: Realities of Culture and Enhancing Cancer Care. Journal of Cancer Education, 26(4), pp.724-733. Available at:

http://www.ncbi.nlm.nih.gov/pubmed/2170 6194 [Accessed May 31, 2017].

Mokuau, N. \& Braun, K.L., 2007. Family support for native Hawaiian women with breast cancer. Journal of Cancer Education, 22(3), pp.191-196. Available at:

http://link.springer.com/10.1007/BF03174 336 [Accessed May 31, 2017].

Pati, S. et al., 2013. Patient navigation pathway and barriers to treatment seeking in cancer in India: A qualitative inquiry. Cancer Epidemiology, 37(6), pp.973-978. Available at: http://www.ncbi.nlm.nih.gov/pubmed/2421 1153 [Accessed May 31, 2017].

Pisu, M. et al., 2010. The out of pocket cost of breast cancer survivors: a review. Journal of cancer survivorship: research and practice, 4(3), pp.202-9. Available at: http://www.ncbi.nlm.nih.gov/pubmed/2040 1542 [Accessed May 31, 2017].

Rankin, S., 2011. Influence of Coping Styles on Social Support Seeking Among Cancer Patient Family Caregivers. Walden Dissertations and Doctoral Studies. Available at: http://scholarworks.waldenu.edu/dissertatio ns/908 [Accessed May 31, 2017].

Walsh, P.M. et al., 2014. Socioeconomic disparity in survival after breast cancer in ireland: observational study. K. Metze, ed. PloS one, 9(11), p.e111729. Available at: http://dx.plos.org/10.1371/journal.pone.01 11729 [Accessed May 31, 2017].

Wanchai, A., Armer, J.M. \& Stewart, B.R., 2010. Breast Cancer Survivors' Perspectives of Care Practices in Western and Alternative Medicine. Oncology Nursing Forum, 37(4), pp.494-500. Available at: http://www.ncbi.nlm.nih.gov/pubmed/2059 1809 [Accessed May 31, 2017].

Yan, B. et al., 2016. Determinants of Quality of Life for Breast Cancer Patients in Shanghai, China R. M. Lafrenie, ed. PLOS ONE, 11(4), p.e0153714. Available at: http://dx.plos.org/10.1371/journal.pone.01 53714 [Accessed May 31, 2017]. 